\title{
Pulmonary function after bone marrow transplantation for chronic myeloid leukaemia
}

\author{
T G SUTEDJA, J F APPERLEY, J M B HUGHES, V R ABER, H G KENNEDY, \\ P NUNN, L JONES, L HOPPER, J M GOLDMAN
}

From the Departments of Medicine and the Medical Physics and the Medical Research Council Leukaemia Unit, Royal Postgraduate Medical School, London

ABSTRACT Pulmonary function was measured before and at intervals after treatment in 44 patients who received a bone marrow transplant for chronic myeloid leukaemia in the chronic phase. All patients were treated with cytotoxic drugs, total body irradiation, and post-graft immunosuppression. Thirty four patients surviving for 12 months were followed at three monthly intervals and 16 patients for 24 months. Fifteen patients received unmanipulated donor marrow cells and 29 patients received donor marrow cells depleted of lymphocytes ex vivo with the monoclonal antibody Campath-1. The 21 patients treated early in this study received $10 \mathrm{~Gy}$ of total body irradiation whereas the 23 patients treated more recently, who were all T lymphocyte depleted, received $12 \mathrm{~Gy}$. Pretransplant lung function for the group was normal and was similar in survivors $(n=34)$ and nonsurvivors $(n=10)$, and in smokers $(n=8)$ and non-smokers $(n=36)$. (Carbon monoxide transfer factor-TLCO) was under $75 \%$ of predicted normal in nine patients before transplantation. TLCO, carbon monoxide transfer coefficient (KCO), $\mathrm{FEV}_{1}$, and vital capacity (VC) values were lower 6 and 12 months after bone marrow transplant than initially. The greatest decline was in TLCO, from an initial value of $89 \%$ to $66 \%$ at 6 and $70 \%$ at 12 months. The 16 longer term survivors showed significant recovery of function between 6 and 24 months after bone marrow transplant for TLCO, KCO, and VC, the increase ranging from $6 \cdot 3 \%$ to $7 \cdot 3 \%$ predicted. Airflow obstruction $\left(\mathrm{FEV}_{1} / \mathrm{VC}\right.$ ratio $\left.<70 \%\right)$ developed in one patient. The major factors associated with deterioration in pulmonary function at 6 and 12 months after transplantation in the 34 survivors (stepwise multiple regression analysis) were (a) transplantation with $\mathrm{T}$ cell depleted donor marrow $(\mathrm{p}<0.005)$ and higher total body irradiation dose ( $\mathrm{p}<0.02)$ with a fall in $\mathrm{KcO}$ and an increase in the $\mathrm{FEV}_{1} / \mathrm{VC}$ ratio; $(b)$ chronic graft versus host disease with a fall in VC (p $<0.01)$; and less fall in KCO (p < 0.01); and $(c)$ acute graft versus host disease with a fall in $\mathrm{FEV}_{1}(\mathrm{p}<0.01)$. It is considered that most patients who survive the short term risks of bone marrow transplant have only minor long term impairment of pulmonary function.

Since the introduction of allogeneic bone marrow transplantation for the treatment of haematological diseases, pulmonary complications, especially opportunistic infections, are recognised as a common cause of morbidity and mortality. ${ }^{1-3}$ Even in the absence of infection, pulmonary function tends to deteriorate over the months after transplantation. The relative contributions of chemotherapy, total body irradia-

Address for reprint requests: Dr J M B Hughes, Department of Medicine, Royal Postgraduate Medical School, Hammersmith Hospital, London W12 0HS.

Accepted 23 November 1987 tion, and graft versus host disease to this decline are poorly understood, and the natural course of lung function after bone marrow transplant in a homogeneous group of patients has not been adequately documented.

We studied prospectively lung volumes and gas transfer capacity before and after bone marrow transplantation in a group of patients with chronic myeloid leukaemia in the first chronic phase, some of whom were grafted with $\mathrm{T}$ lymphocyte depleted marrow. The data were analysed to assess the magnitude of the lung injury and possible differences between treatment protocols. 


\section{Methods}

Fifty five patients with chronic myeloid leukaemia in chronic phase received allogeneic bone marrow transplants from first degree relatives matched for HLA genotype from January 1981 to January 1986. Of these, $\mathbf{4 4}$ have been followed prospectively with lung function tests (table 1). All patients had been previously treated with a chemotherapy regimen containing busulphan, hydroxyurea, or 6-thioguanine, alone or in combination. Before bone marrow transplantation patients received a single dose of daunorubicin $60 \mathrm{mg} / \mathrm{m}^{2}$, two doses of cyclophosphamide 60 $\mathrm{mg} / \mathrm{kg}$, and total body irradiation with a Philips 8 $\mathrm{MeV}$ linear accelerator, fractionated to a total dose of $10 \mathrm{~Gy}(\mathrm{n}=21)$ or $12 \mathrm{~Gy}(\mathrm{n}=23)$. Fractions of $2 \mathrm{~Gy}$ were given over three days at a dose rate of $15 \mathrm{cGy} /$ min. Cyclosporin, used as prophylaxis against graft versus host disease, was started on the day before bone marrow transplantation and continued for six months. ${ }^{4}$ Twenty nine patients were given bone marrow depleted of $\mathrm{T}$ lymphocytes ex vivo by incubation with the monoclonal antibody Campath-1. Most $(22 / 29)$ of this group received $12 \mathrm{~Gy}$ total body irradiation to prevent graft failure associated with $T$ cell depleted transplants. Graft versus host disease when clinically diagnosed was usually confirmed by biopsy and graded as described by Thomas et al.' Acute graft versus host disease was treated with methylprednisolone $1-20 \mathrm{mg} / \mathrm{kg} /$ day, depending on the severity. Chronic graft versus host disease was treated with prednisolone or azathioprine or both. Pneumonitis was diagnosed from the presence of interstitial infiltrates on the chest radiograph accompanied by fever, tachypnoea, and arterial hypoxaemia.

Chest radiographs and lung function tests were carried out at regular intervals. Spirometry was per-

Table 1 Clinical data on the 44 patients

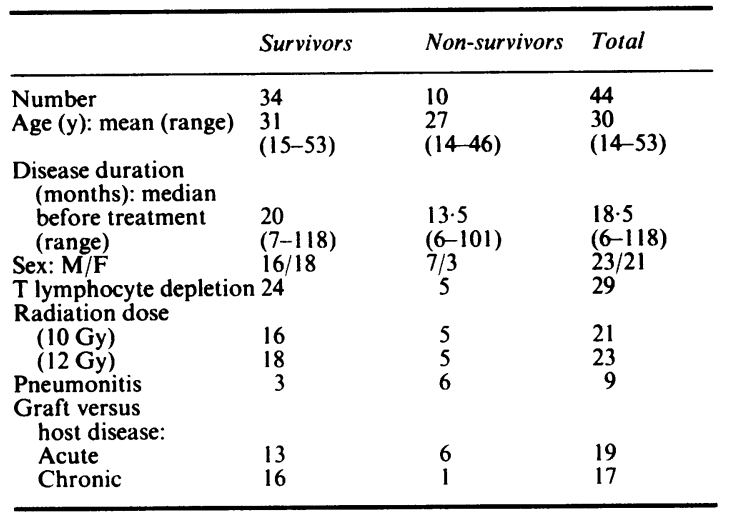

formed with a Vitalograph for the forced expiratory volume in one second $\left(\mathrm{FEV}_{1}\right)$ and the relaxed vital? capacity (VC). P K Morgan transfer test apparatus등 was used to measure the single breath carbon mono- $\overline{\frac{\bar{N}}{5}}$ xide transfer coefficient (KCo), the carbon monoxide $\widetilde{\widetilde{\sigma}}$ diffusing capacity (transfer factor-TLCo), and the alveolar volume at maximal inspiration (from the 10 \% second helium dilution-VA). KCO and TLCo were $\vec{\circ}$ corrected for the current haemoglobin concentration..$^{5^{\circ}}$ The mean of the two or three best measurements was $\omega_{\mathscr{O}}$ taken. Normal values were obtained from Quanjer for + lung volumes ${ }^{6}$ and from Bradley for KCo and TLCo. ${ }^{7 \times}$ Five patients (aged 16-38 years) were current smokers $\vec{\omega}$ (10-30 cigarettes a day)-three of 34 survivors and two of 10 non-survivors. Three surviving patients had $\vec{\omega}$ stopped smoking more than one year previously.

Stepwise multiple regression analysis was per-은 formed on data from patients surviving 12 months $\vec{Z}$ $(n=34)$ to investigate the effects of age, sex, lymphocyte depletion, acute and chronic graft versus hostô亍 disease, total body irradiation, occurrence of $\vec{\theta}$ pneumonitis, and duration of disease before boneco marrow transplantation on lung function measurements before transplantation and on theo changes in lung function six and 12 months after. Sinces many regression analyses were done on the sameo patients, the $p$ value obtained for any one variableo should be viewed with caution; it may be prudent to@ consider $p<0.01$ as the test of statistical significance. $\vec{B}$

\section{Results}

Table 1 shows the clinical data for survivors and non survivors. Recipients of $\mathrm{T}$ cell depleted marrow cellso had a higher incidence of relapse and pneumonitis acute graft versus host disease was uncommon (6/29) in this group and more common (13/15) in recipients of unmanipulated donor cells. In survivors chronico graft versus host disease was slightly less common $(11 \vec{R}$ /24) in $T$ cell depleted patients $(5 / 10$ in non- $T$ celP depleted patients) and clinically it was less severe.

Pneumonitis occurred in nine patients, six of whom died. Four of these deaths were associated with opportunist infections. Survival was significantly" associated with the absence of acute graft versus hosi disease $(p<0.05)$ and, not surprisingly, with thew absence of pneumonitis ( $p<0.001)$.

Before bone marrow transplantation lung functiono measurements were essentially normal and there waso no significant difference between survivors and non? survivors (table 2). Few of the 44 patients had valueso less than $75 \%$ predicted (three for $\mathrm{FEV}_{1}$ and $\mathrm{VC}$, one for KCO and nine for TLCO). Only one patient had am $\mathrm{FEV}_{1} / \mathrm{VC}$ ratio under $70 \%(66 \%)$. A TLCO of unde $\mathbb{B}$ $75 \%$ occurred in $6 / 34$ (lowest value $65 \%$ ) survivorso and in $3 / 10$ (lowest value $56 \%$ ) non-survivors. Pul 

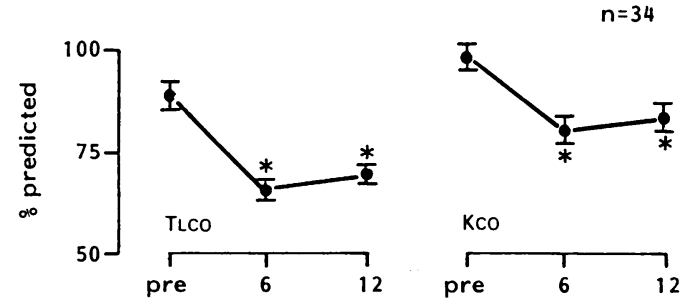

Table 2 Mean (SD) pulmonary function (percentages of predicted values) before bone marrow transplantation

\begin{tabular}{lccc}
\hline & $\begin{array}{l}\text { Survivors } \\
(n=34)\end{array}$ & $\begin{array}{l}\text { Non-survivors } \\
(n=10)\end{array}$ & Total \\
\hline TLCO & $89(14)$ & $90(23)$ & $89(16)$ \\
KCO & $99(18)$ & $101(24)$ & $100(19)$ \\
VA $(\%$ pred TLC) & $87(12)$ & $85(8)$ & $87(11)$ \\
VC & $100(16)$ & $99(18)$ & $100(16)$ \\
FEV $/$ VC $^{*}$ & $85(8)$ & $86(7)$ & $85(8)$ \\
FEV & $99(15)$ & $98(16)$ & $99(15)$ \\
\hline
\end{tabular}
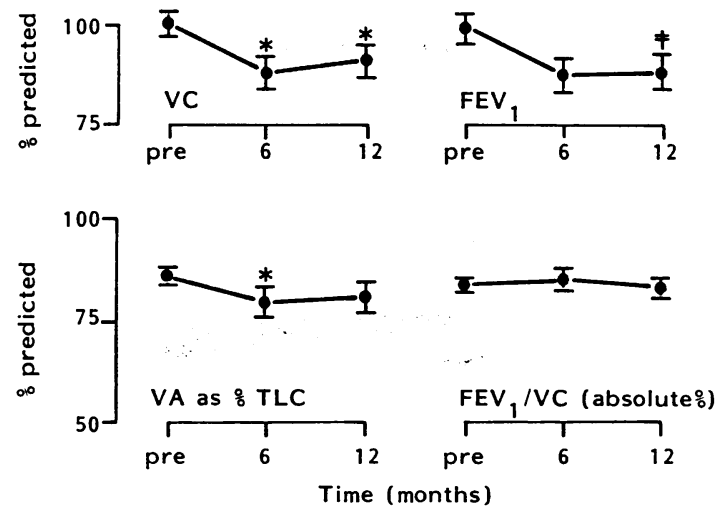

*Actual not predicted ratio.

TLCO-carbon monoxide transfer factor; $\mathrm{KCO}-$ transfer coefficient; VA-alveolar volume; VC-vital capacity.

monary function in smokers $(\mathrm{n}=5)$ and ex-smokers $(n=3)$ did not differ from the rest of the group (analysis of variance) but the numbers were small. Multiple regression analysis did not show any effect of any other factors on pulmonary function before transplantation.

The lung function data of 34 patients who survived more than 12 months after transplantation showed a significant decline in pulmonary function, maximal six months after transplantation, and subsequently a gradual improvement (fig 1). The $\mathrm{FEV}_{1} / \mathrm{VC}$ ratio did not change. Multiple regression analysis of the data on these 34 patients showed a significant influence of acute graft versus host disease on the decline in $\mathrm{FEV}_{1}$ and alveolar volume ( $\mathrm{VA}_{\mathrm{A}}$ ) when the 12 month values were compared with pre-transplantation values (fig 2).

Acute CVHD
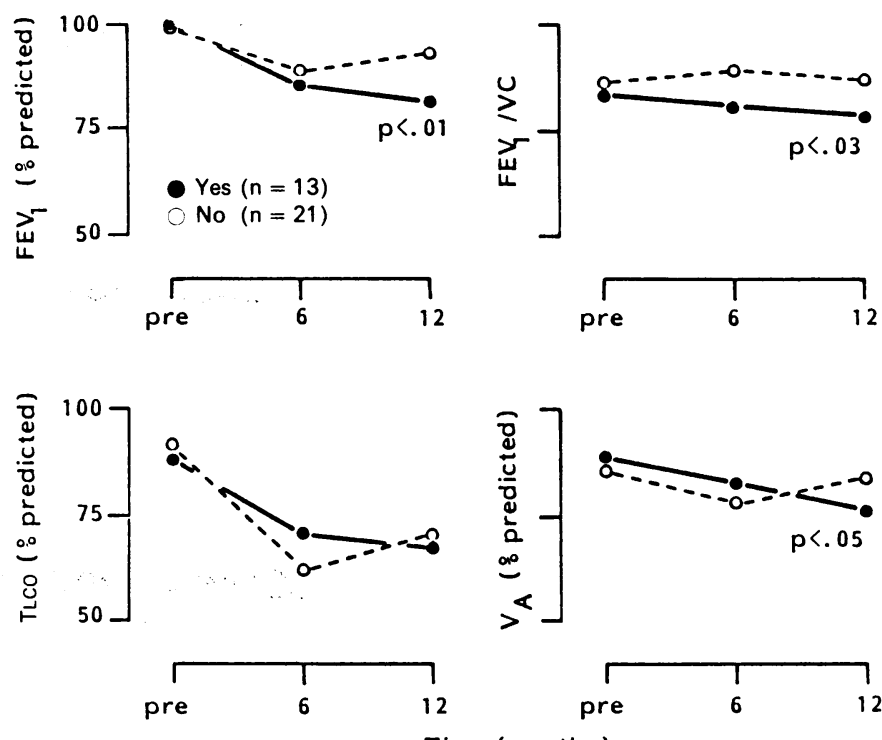

Time (months)

Fig 2 Effect of acute graft versus host disease on pulmonary function in 34 patients surviving at least 12 months. $p$ values show significant effects of acute graft versus host disease in relation to initial values from multiple regression analysis. 

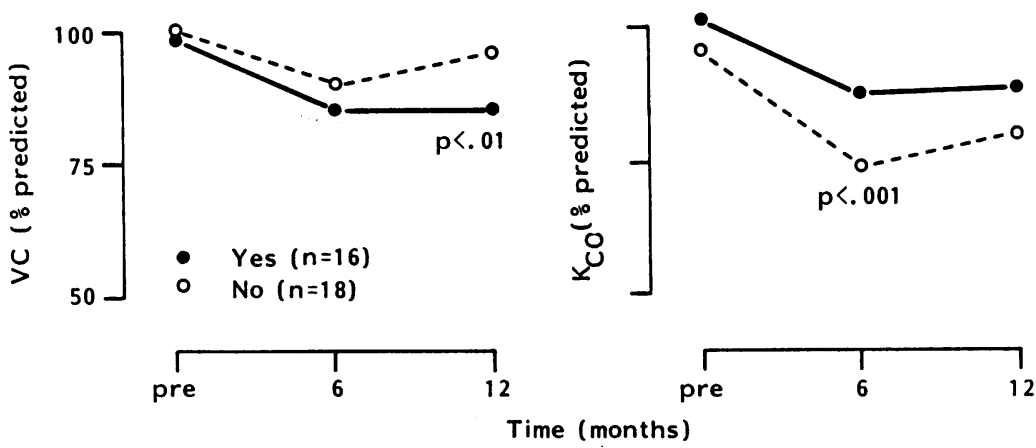

Fig 3 Effect of chronic graft versus host disease (GVHD) on vital capacity $(V C)$ and transfer coefficient (KCO) in 34 patients surviving at least 12 months. $p$ values show significant effects of chronic graft versus host disease in relation to initial values from multiple regression analysis.

T Iymphocyte depletion
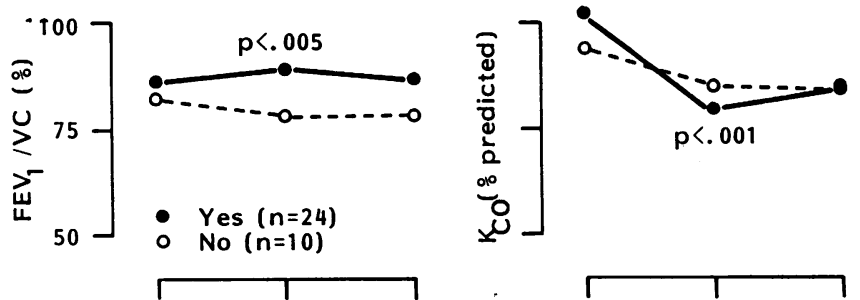

Total body irradiation
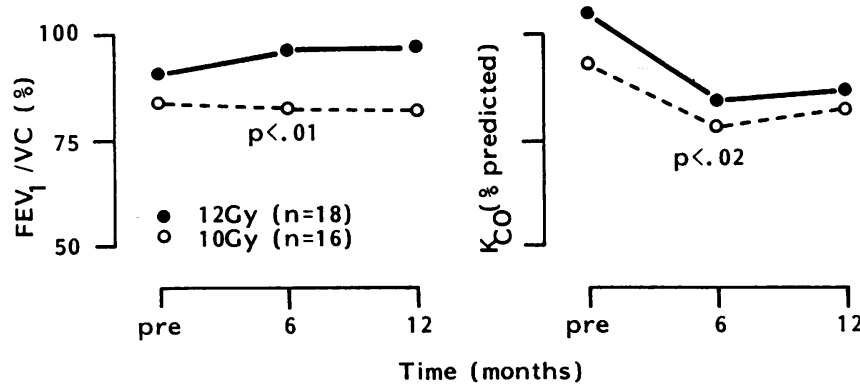

Fig 4 Effect of $T$ lymphocyte depletion and level of total body irradiation on FEV $/$ vital capacity (VC) ratio (absolute \%) and transfer coefficient (KCO) (\% predicted) in 34 patients surviving at least 12 months. $p$ values show significant effects of $T$ lymphocyte depletion and total body irradiation in relation to initial values from multiple regression analysis. 


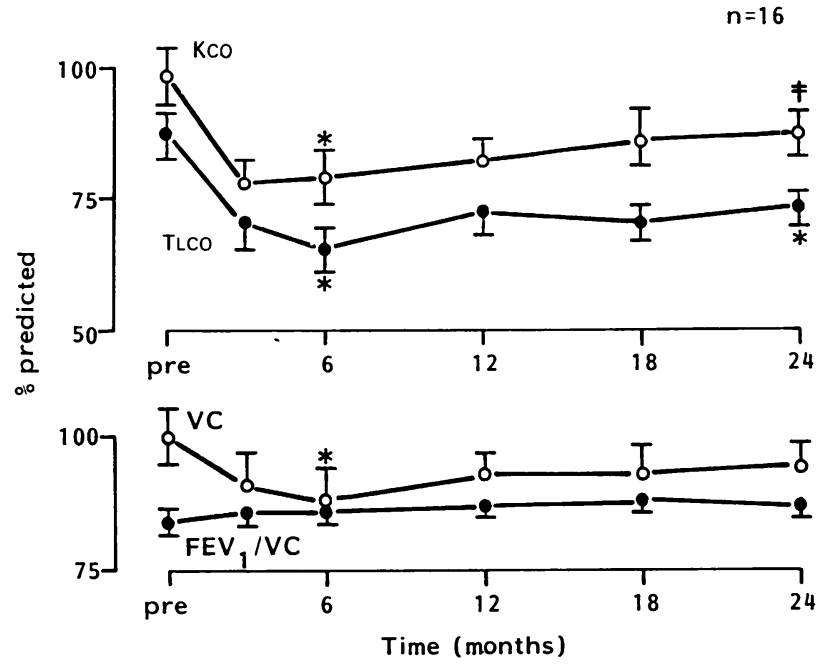

Fig 5 Long term changes in pulmonary function (mean and $S D$ ) in 16 patients surviving for at least two years after bone marrow transplantation. ${ }^{*} p<0.001 ; \ddagger p<0.005$.

There was also a significantly lower $\mathrm{FEV}_{1} / \mathrm{VC}$ ratio at 12 months in those who had had acute graft versus host disease, though the absolute values were still within the normal range. Chronic graft versus host disease was associated with a larger fall in vital capacity and a smaller fall in Kco (fig 3 ). Since Kco is diffusing capacity per unit of accessible lung volume, relative preservation of $\mathrm{KCO}$ will occur if destruction of alveolar units is patchy and blood volume is diverted from the damaged alveoli to unaffected areas of lung.

$T$ lymphocyte depletion and the larger dose of total body irradiation (12 Gy) were both associated on multiple regression analysis with an increase in the $\mathrm{FEV}_{1} / \mathrm{VC}$ ratio and a greater fall in KCo (fig 4), suggesting pulmonary fibrosis.

The sixteen patients followed for at least 24 months showed significant recovery in TLCO, KCO, and vital capacity at 24 months by comparison with 6 months (fig 5). As percentages of predicted values TLCO rose by $7.3 \%(p=0.015$, Wilcoxon matched pairs ranked sum test), Kco by $7.4 \%(p=0.023)$, and VC by $6.3 \%$ $(\mathrm{p}=0.031)$.

\section{Discussion}

Lung function after bone marrow transplant has been studied previously but these studies were retrospective, lacked consistent lung function data before transplantation, and comprised heterogeneous groups of patients with different types of leukaemia or aplastic anaemia. ${ }^{8-11}$ Various changes in pulmonary function were reported, the occurrence of airflow obstruction being noted in some studies 911 and the fall in TLCO in others. ${ }^{810}$

\section{LUNG FUNCTION BEFORE TRANSPLANTATION}

Previous series, consisting mainly of patients with acute myeloid leukaemia, have reported reductions in TLCO or KCO to $70-80 \%$ predicted $^{81011}$ before bone marrow transplantation, although $\mathrm{FEV}_{1}$ and vital capacity were generally normal. Possible causes of reduction in TLCO before transplantation, such as interstitial infiltration by leukaemia, vascular changes secondary to chemotherapy with busulphan and 6thioguanine, and bacterial and viral infections, have been discussed before. ${ }^{1213}$ Low ThCo values $(<75 \%)$ occurred in $20 \%$ of patients in this series but there was no correlation with survival. Otherwise, all pre-transplantation values in the present series were within normal limits, although there was substantial variation in measurements from patient to patient. Multiple regression analysis did not show any significant effect of duration of disease on any lung function measurement before transplantation. Thus the patients in this series were homogeneous in functional terms. There was no difference in pre-bone marrow transplant lung function between survivors and nonsurvivors and pulmonary function before transplantation was therefore not a prognostic factor for survival. Smoking similarly had no effect on lung function before transplantation or on subsequent progress, but the number of patients (five) is too small for general conclusions to be drawn. Depledge et al ${ }^{8}$ came to similar conclusions with a larger number of smokers $(21 / 48)$. 
LUNG FUNCTION AFTER TRANSPLANTATION

As in previous studies, ${ }^{810}$ TLCO was the most sensitive index, with an immediate decline after transplantation. None of the changes was particularly large. The greatest change (in the 16 patients followed for 24 months) was in TLCO, which fell from $88 \%$ (SD 16\%) predicted before transplantation to $65 \%(16 \%)$ at 6 months, recovering to $72 \%(12 \%)$ at 24 months. In absolute terms the decline of TLCO and KCO were greatest in those with higher initial values, so there was a proportional decrease six months after transplantation. All values started to recover slowly nine months after transplantation.

\section{INFLUENCE OF GRAFT VERSUS HOST DISEASE}

The incidence of interstitial pneumonia ${ }^{15}$ and severe airflow obstruction has been higher in patients with severe acute and chronic graft versus host disease, and some patients have had histological evidence of obliterative bronchiolitis. $^{891116-18}$ In our prospective study chronic graft versus host disease was associated with a greater fall in vital capacity at 12 months (fig 3) but not with airflow obstruction. In contrast to the previous experience of our group, ${ }^{9}$ we have recently had only one case of severe airflow obstruction suggesting obliterative bronchiolitis, the patient ultimately dying of disseminated toxoplasmosis. The reduction in both the incidence and the severity of chronic graft versus host disease in the present series might explain this finding. The changes associated with acute graft versus host disease (fig 2) were compatible with loss of functioning lung units (volume reduction), but $\mathrm{TLCO}_{\mathrm{L}}$ and $\mathrm{KCO}$ were not affected specifically.

\section{INFLUENCE OF T CELL DEPLETION}

$T$ cell depletion of donor marrow effectively reduces the incidence and severity of graft versus host disease, but appears to increase the risk of recurrence of disease in chronic myeloid leukaemia. ${ }^{14}$ Patients who received $\mathrm{T}$ cell depleted donor marrow had lower morbidity and mortality rates immediately after transplantation but, surprisingly, $\mathrm{T}$ cell depletion resulted in a greater decline in $\mathrm{KCO}$ at 6 months and a rise in the $\mathrm{FEV}_{1} / \mathrm{VC}$ ratio, suggesting the development of lung fibrosis (fig 4). Because most patients in this group (22/29) were exposed to the higher total body irradiation dose of 12 Gy, which in the multiple regression analysis was associated with similar changes, the influence of $\mathrm{T}$ cell depletion per se remains unresolved.

\section{INFLUENCE OF TOTAL BODY IRRADIATION}

Although total body irradiation is used in part to kill leukaemia stem cells, it has proved difficult to define the optimal dose rate, total dose, and fractionation schedules for this purpose. There are several variables, such as individual sensitivity, tumour burden, and putative graft versus leukaemia effect to be taken intō account. ${ }^{19} \mathrm{~A}$ total dose above $8 \mathrm{~Gy}$ and a dose rateo higher than $5.7 \mathrm{cGy} / \mathrm{min}$ have been correlated with a $\overline{\bar{c}}$ higher incidence of pneumonitis. ${ }^{151920}$ Multiple regression analysis showed that the higher total bodyo irradiation dose ( 12 rather than $10 \mathrm{~Gy}$ ) was associated with changes in $\mathrm{FEV}_{1} / \mathrm{VC}$ and $\mathrm{KcO}$, which would be. expected if irradiation damage had progressed to lung $\vec{\overrightarrow{ }}$ fibrosis. ${ }^{21}$ Pneumonitis was more common in theo patients receiving $12 \mathrm{~Gy}$ of total body irradiation ( $7 / \overrightarrow{\hat{x}^{2}}$ 23) than in those receiving a dose of $10 \mathrm{~Gy}(3 / 21)$ although this difference did not reach statistical sig $\omega$ nificance. The occurrence of pneumonitis had now influence on changes in pulmonary function after transplantation, perhaps because most patients with pneumonitis died within six months of transplantation and were therefore not included in the multiples regression analysis.

Current bone marrow transplant regimens pose $\frac{\widehat{\rho}}{\mathrm{P}}$ moderate risk for the lungs but impairment ofo pulmonary function in patients who survive seems to be moderate and not progressive after the first six months. Risk factors associated with a decline in pulmonary function include total body irradiation, Iิ cell depletion, and graft versus host disease, but no single factor is particularly important. These result are applicable only to patients with chronic myeloid leukaemia and other factors, such as the underlying disease, opportunist infections, conditioning regimens, and treatment before transplantation should be considered in the assessment of pulmonary morbidity and mortality in other conditions.

\section{References}

1 Thomas ED, Storb R, Clift RA, et al. Bone marrovi transplantation [two parts]. $N$ Engl J Med 1975? 292:832-43, 895-902.

2 Prentice HG. A review of the current status and tech niques of allogeneic bone marrow transplantation for the treatment of leukaemia. J Clin Pathol 1983을. 36: 1207-14.

3 Clift RA, Thomas ED, Fefer A, et al. Treatment of chronic granulocytic leukaemia in chronic phase by allogeneic marrow transplantation. Lancet 1982 N ii: $621-3$.

4 Powles RL, Morgenstern G, Selby PJ, et al. Cyclosporitr A to prevent graft-versus-host disease in man aftê allogeneic bone marrow transplantation. Lancet $1980 \mathbb{E}$ i:327-9.

5 Cotes JE, Dabbs JM, Elwood PC, Hall AM, McDonaldD A, Saunders MJ. Iron deficiency anaemia: its effect on? transfer factor for the lung (diffusing capacity) an\& ventilation and cardiac frequency during submaximaగ⿱ exercise. Clin Sci 1972;42:325-35.

6 Quanjer PH, ed. Standardised lung function testing. Report of working party for European Community fo 
coal and steel. Bull Eur Physiopathol Respir 1983;19(suppl 5):7-10.

7 Bradley J, Bye C, Hayden SP, Hughes DTD. Normal values of transfer factor and transfer coefficients in healthy males and females. Respiration 1979;38:221-6.

8 Depledge MH, Barrett A, Powles RL. Lung function after bone marrow grafting. Int $J$ Radiat Oncol Biol Phys 1983;9:145-51.

9 Wyatt SE, Nunn P, Hows JM, et al. Airways obstruction associated with graft versus host disease after bone marrow transplantation. Thorax 1984;39:887-94.

10 Sorenson PG, Ernst P, Panduro J, Moller J. Reduced lung function in leukaemia patients undergoing bone marrow transplantation. Scand J Haematol 1984; 32:253-7.

11 Link H, Reinhard U, Blaurock M, Ostyendorf P. Lung function changes after allogeneic bone marrow transplantation. Thorax 1986;41:508-12.

12 Sloane JP, Depledge HM, Powles RL, Morgenstern GR, Trickley BS, Dady PJ. Histopathology of the lung after bone marrow transplantation. J Clin Pathol 1983;36:546-54.

13 Cooper JAD, White DA, Matthay RA. Drug-induced pulmonary disease: 1 -Cytotoxic drugs. Am Rev Respir Dis 1986;133:321-40.

14 Apperley JF, Jones L, Hale G, et al. Bone marrow transplantation for patients with chronic granulocytic leukaemia: T-cell depletion with Campath-1 reduces the incidence of graft-versus-host disease but may increase the risk of leukaemic relapse. Bone Marrow Transplantation 1986;1:53-66.

15 Keane TJ, Van Dijk, Rider WD. Idiopathic interstitial pneumonia following bone marrow transplantation: the relation with total body irradiation. Int $J$ Radiat Oncol Biol Phys 1981;7:1365-70.

16 Roca J, Granena A, Rodriguez-Roisin R, Alvarez P, Agusti-Vidal A, Rozman C. Fatal airway disease in an adult with chronic graft-versus-host disease. Thorax 1982;37:77-8.

17 Ralph DD, Springmeyer SC, Sullivan KM, Hackman RC, Storb R, Thomas ED. Rapidly progressive airflow obstruction in marrow transplant recipents. $\mathrm{Am}$ Rev Respir Dis 1984;129:641-4.

18 Beschorner WE, Saral R, Hutchins GM, Tutschka J, Santos GW. Lymphocytic bronchitis associated with graft-versus-host disease in recipients of bone marrow transplants. N Engl J Med 1978;299:1030-6.

19 Barrett A. Clinical aspects of total body irradiation. J Eur Radiother 1982;4:159-64.

20 Bortin MM, Kay HEM, Gale RP, Rimm AA. Factors associated with interstitial pneumonitis after bone marrow transplantation for acute leukaemia. Lancet 1987;i:437-9.

21 Gibson GJ, Pride NB. Pulmonary mechanics in fibrosing alveolitis: the effects of lung shrinkage. Am Rev Respir Dis 1977;116:637-47. 